Original Article

\title{
A Study to Assess the Awareness of III Effects of Tobacco among Adolescents and Young Adults of Mangalore
}

\author{
Abidh Ibrahim ${ }^{1}$, Stacy Babun Mathew ${ }^{1}$, Sudipta S. Arekal ${ }^{1}$, Swathi, $^{1}$ Santhosh $^{2} \&$ Rashmi Kundapur $^{3}$ \\ ${ }^{1}$ M BBS Students, ${ }^{2}$ M edico Social Worker, ${ }^{3}$ Professor, Department of Community M edicine, K.S. Hegde M edical Academy, \\ Nitte University, M angalore, Karnataka, India.
}

*Corresponding Author :Rashmi Kundapur, Professor, Department of Community Medicine, K. S. Hegde Medical Academy, Nitte University, M angalore-575018, Karnataka, India. M obile : +919880496567 E-mail: dr.rashmi.kundapur@gmail.com

$\begin{array}{ll}\text { Received } & : 21-08-2014 \\ \text { Review Completed } & : 29-07-2016 \\ \text { Accepted } & : 17-08-2016\end{array}$

Keywords : Tobacco, awareness, adolescent students

\begin{tabular}{|c|}
\hline Access this article online \\
\hline Quick Response Code \\
\hline
\end{tabular}

\begin{abstract}
:
Introduction : Tobacco use among school children is becoming a serious problem in developing countries. The early age of initiation underscores the urgent need to intervene and protect this vulnerable group from falling prey to this addiction. Tobacco use is a leading cause of preventable deaths world over, more so in developing countries. The tobacco situation in India is unique because of a vast spectrum of tobacco products available for smoking as well as smokelessuse.
\end{abstract}

Aims and Objectives: To assess the awareness of risk factors and consequences of tobacco use among adolescent and young adults.

Materials and Method : M aterials used are - Questionnaire pertaining to the awareness of smoking.

Methodology : Assessment of awareness and knowledge of tobacco smoking was done by means of answeringa pretested validated questionnaire with annonimity.

Results : According to the study $78.23 \%$ said that they were aware of effects of smoking on health.39.83\% and $14.78 \%$ thought it would lead to lung disease and heart disease respectively. $7.8 \%$ of the smokers were aware that smoking leads to cancer

Conclusion: According to the study, $78.23 \%$ of the study sample were aware of harmful effects of tobacco use on health.

\section{Introduction}

Tobacco use is a leading cause of preventable deaths world over, more so in developing countries. The tobacco situation in India is unique because of a vast spectrum of tobacco products available for smoking as well as smokeless use .Smoking of cigarette particularly beedi and chewing tobacco (smokeless use) is an age-old practice in India.

There are only a few studies on prevalence and initiation of smoking and smokeless to bacco use among children in our country $;^{1}$. In the study conducted in 2004 by the WHO shows that women who smoke run even more risk than men. ${ }^{2}$ Osteoporosis is accelerated with tobacco use. Tobacco use is also associated with higher risk of spontaneous miscarriages. The risks of tobacco use are highest among those who start early and continue its use for a long period. The early age of initiation underscores the urgent need to intervene and protect this vulnerable group from falling prey to this addiction. The most common reasons cited for children to start using tobacco are peer pressure, parental tobacco habits and pocket money given to children. The present cross-sectional study was undertaken to determine the knowledge and practices of alcohol, tobacco and other substance abuse among young individualsin schools and colleges of $\mathrm{M}$ angalore.

Every year hundreds of thousands of people around the world die from diseases caused by smoking cigarettes -Smoking kills. Tobacco smoke also contributes to a number of cancers. The mixture of nicotine and carbon monoxide in each cigarette increases heart rate and blood pressure, straining the heart and blood vessels.This can cause heart attacks and stroke. It slows blood flow, cutting 
off oxygen to feet and hands. Some smokers end up having their limbsamputated.

\section{Objectives}

To assess the awareness of risk factors and consequences of to bacco use among adolescent and young adults.

\section{Material Methods}

Community based cross-sectional study conducted in different schools and colleges of M angalore. They includeSt. Aloysius Degree College, NITTE PU College, K.S.Hegde Medical Academy, Roshini Nilaya School and Vishwamangala PU College. Students from the above said colleges were the study samples. Taking $20 \%$ awareness as baseline the sample size was calculated with $80 \%$ power of the study and $95 \%$ confidence interval, the sample size was calculated to be 400 with relative precision being $20 \%$ (power of study $80 \%$ ). Considering $20 \%$ non response, we considered to interview 480 students. Universal sampling in the colleges we selected was done for students. Our total sample was 487. A questionnaire consisting of questions that were based on the perception, knowledge of tobacco use and its consequences was prepared. Reliability and face validity of the questionnaire was done and linguistic validation was done. The questionnaire was to be filled anonymously. Sufficient time was given to the students to complete the questionnaire. Only students willing to participate with consent given were included. The data obtained were compiled in M icrosoft excel and the results were tabulated in proportions and cross tables. Association of gender was done.

\section{Result}

According to the study $78.23 \%$ said that they were aware of effects of smoking on health (Table no: 1). among them $39.83 \%$ and $14.78 \%$ thought it would lead to lung disease and heart disease respectively. And $7.8 \%$ of the smokers were aware that smoking leads to cancer. But 3.08\%, $16.83 \%$ said that it would lead to diabetes \& impotence respectively (fig no: 1). Rest of the students said that smoking leads to infections and psychological effects. 70.63 $\%$ of the students planned to be a non smoker in future.
Table 1 : Awareness about effects of smoking on health $(n=487)$

\begin{tabular}{|l|c|c|}
\hline & Number & Percentage \\
\hline Yes & 381 & 78.23 \\
\hline No & 54 & 11.08 \\
\hline Not Answered & 52 & 10.67 \\
\hline
\end{tabular}

Fig. 1 : \% showing awareness of effects due to smoking

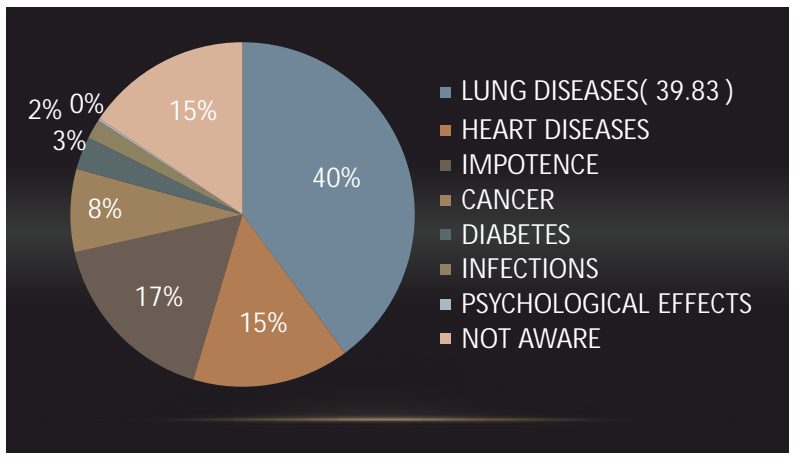

\section{Discussion}

Smoking is one of the most common forms of recreational drug use. Tobacco smoking is today by far the most popular form of smoking and is practiced by over one billion people in the majority of all human societies. According to our study $70.19 \%$ of students opted to be nonsmokers in the future .This result can be supported by two studies ${ }^{1,3}$, which showed that students opted to be nonsmokers because of the health risks of smoking and the social stigma associated with it. It showed $95.1 \%$ adolescents indicating negative perception about male smokers and $74.9 \%$ about females. Study done across the USA, Canada, the UK and Australia ${ }^{4}$ showed that our sample students had limited knowledge about the complications and consequences of smoking .About $15.45 \%$ of our students were not aware of any complications listed in our questionnaire like lung diseases, cardio-vascular diseases, impotence, cancer, diabetes, infections and psychological effects .According to Global Adult Tobacco Survey, India (2009-2010), the prevalence of overall tobacco use among males is $48 \%$ and that among females is $20 \%{ }^{5}$. As public awareness of the health risks of tobacco use increases, smoking rates decline. Evidence-based mass media campaigns encourage smokers to quit. M ost people agree that tobacco is harmful to health; however, smokers tend to underestimate the extent of the risks. In many developing countries, there is very little public information about the health risks of 
tobacco use.

\section{Limitations}

Our study captures only few factors regarding awareness of smoking, hence it cannot explain all the reasons for a student to take up a habit of smoking. This study do not

\section{References}

1. VN Shah, PB Verma, CB Tripathi-Indian Journal of Community...., 2005medin.nic.in. Knowledge, Attitude and Practice regarding Tobacco Consumption among the college students of Bhavnagar City (Gujarat)

2. WHO (2004), Building Blocks for Tobacco Control: A Hand Book.

3. Gajalakshmi V, Peto R, Kanaka TS, Jha P. Smoking and mortality from tuberculosis and other diseases in india.

4. World Developmental Report 1993,Investing in Health, Published for the World Bank, Oxford University Press

5. Govt. of India (2010), Gobal Adult Tobacco Survey, GATSIndia 2009-10. Executive Summary, M inistry of Health and Family Welfare, New Delhi. have representative sample from all colleges.

\section{Conclusion}

According to the study, $78.23 \%$ of the study sample were aware of harmful effects of tobacco use on health. 